Biomath Communications

\title{
Research Articles in Peer-Reviewed Journals from Past BIOMATH conferences ${ }^{1}$
}

Tihomir Ivanov

The past biomathematical conferences in Sofia (Biomath-1995, Destobio1997, MMSC-2009, Biomath-2011, Biomath-2012, Biomath-2013, Biomath2014) resulted in a total number of 179 original research journal articles, as follows: 4 articles in J.UCS, 34 articles in Mathematical Biosciences, 59 articles in Computers \& Mathematics with Applications, 12 articles in Serdica Journal of Computing, 14 articles in B\&BE and 56 articles in journal BIOMATH. A list of titles of these articles follows.

Journal of Universal Computer Science (J. UCS), Volume 2, Issue 2, Pages 59-95

http://dx.doi.org/10.3217/jucs-002-02

S. M. Markov, Y. Akyildiz, Curve Fitting and Interpolation of Biological Data Under Uncertainties, Journal of Universal Computer Science (J. UCS), vol. 2, no. 2 (1996), 59-69

http://dx.doi.org/10.3217/jucs-002-02-0058

P. Tsanova Andreeva, Inexact Information Systems and its Application to Approximate Reasoning, Journal of Universal Computer Science (J. UCS), vol. 2, no. 2 (1996), 70-76

http://dx.doi.org/10.3217/jucs-002-02-0070

D. Lavenier, Dedicated Hardware for Biological Sequence Comparison, Journal of Universal Computer Science (J. UCS), vol. 2, no. 2 (1996), $77-86$

http://dx.doi.org/10.3217/jucs-002-02-0077

1 Citation: T. Ivanov, Research Articles in Peer-Reviewed Journals from Past BIOMATH conferences. Biomath Communications 1/2 (2014) http://dx.doi.org/10. $11145 /$ j.bmc.2015.03.101 
D. A. Mac Dónaill, On the Scalability of Molecular Computational Solutions to NP Problems, Journal of Universal Computer Science (J. UCS), vol. 2 , no. 2 (1996), 87-95

http://dx.doi.org/10.3217/jucs-002-02-0087

Mathematical Biosciences 156(1-2), pp. 1-338 http://www.sciencedirect.com/science/journal/00255564/156

Carlos A. Braumann, Variable effort fishing models in random environments, Mathematical Biosciences 156 (12), 1999, 1-19.

http://dx.doi.org/10.1016/S0025-5564(98)10058-5

Ingemar Nasell, On the quasi-stationary distribution of the stochastic logistic epidemic, Mathematical Biosciences 156 (12), 1999, 21-40.

http://dx.doi.org/10.1016/S0025-5564(98)10059-7

Frank Ball, Stochastic and deterministic models for SIS epidemics among a population partitioned into households, Mathematical Biosciences 156 (12), 1999, 41-67.

http://dx.doi.org/10.1016/S0025-5564(98)10060-3

Wai-Yuan Tan, Zhihua Xiang, Some state space models of HIV pathogenesis under treatment by anti-viral drugs in HIV-infected individuals, Mathematical Biosciences 156 (12), 1999, 69-94.

http://dx.doi.org/10.1016/S0025-5564(98)10061-5

Charles J Mode, Candace K Sleeman, A new design of stochastic partnership models for epidemics of sexually transmitted diseases with stages, Mathematical Biosciences 156 (12), 1999, 95-122.

http://dx.doi.org/10.1016/S0025-5564(98)10062-7

Candace K. Sleeman, Charles J. Mode, A computer exploration of some properties of non-linear stochastic partnership models for sexually transmitted diseases with stages, Mathematical Biosciences 156 (12), 1999, 123-145. http://dx.doi.org/10.1016/S0025-5564(98)10063-9

Linda Rass, John Radcliffe, The derivation of certain pandemic bounds, Mathematical Biosciences 156 (12), 1999, 147-165.

http://dx.doi.org/10.1016/S0025-5564(98)10064-0

Sabine Stöcker, Models for tuna school formation, Mathematical Biosciences 156 (12), 1999, 167-190.

http://dx.doi.org/10.1016/S0025-5564(98)10065-2

Mario Markus, Dominik Böhm, Malte Schmick, Simulation of vessel morphogenesis using cellular automata, Mathematical Biosciences 156 (12), 
1999, 191-206.

http://dx.doi.org/10.1016/S0025-5564(98)10066-4

Wolfgang Alt, Micah Dembo, Cytoplasm dynamics and cell motion: two-phase flow models, Mathematical Biosciences 156 (12), 1999, 207-228. http://dx.doi.org/10.1016/S0025-5564(98)10067-6

R. Díaz-Sierra, B. Hernández-Bermejo, V. Fairén, Graph-theoretic description of the interplay between non-linearity and connectivity in biological systems, Mathematical Biosciences 156 (12), 1999, 229-253.

http://dx.doi.org/10.1016/S0025-5564(98)10068-8

Andreas Deutsch, Anna T. Lawniczak, Probabilistic lattice models of collective motion and aggregation: from individual to collective dynamics, Mathematical Biosciences, 156 (12), 1999, 255-269.

http://dx.doi.org/10.1016/S0025-5564(98)10069-X

David M Holloway, Lionel G Harrison, Suppression of positional errors in biological development, Mathematical Biosciences, 156 (12), 1999, 271290.

http://dx.doi.org/10.1016/S0025-5564(98)10070-6

John Radcliffe, Linda Rass, Strategic and genetic models of evolution, Mathematical Biosciences 156 (12), 1999, 291-307.

http://dx.doi.org/10.1016/S0025-5564(98)10071-8

Eckhard Finke, Gottfried Jetschke, How inbreeding and outbreeding influence the risk of extinction a genetically explicit model, Mathematical Biosciences 156 (12), 1999, 309314.

http://dx.doi.org/10.1016/S0025-5564(98)10072-X

Junji Maruyama, Hiromi Seno, Mathematical modelling for intra-specific brood-parasitism: coexistence between parasite and non-parasite, Mathematical Biosciences, 156 (12), 1999, 315-338.

http://dx.doi.org/10.1016/S0025-5564(98)10073-1

Mathematical Biosciences 157(1-2), pp. 1-372 http://www.sciencedirect.com/science/journal/00255564/157

Maia Martcheva, Exponential growth in age-structured two-sex populations, Mathematical Biosciences Biosciences 157 (12), 1999, 1-22.

http://dx.doi.org/10.1016/S0025-5564(98)10074-3

Jacek Waniewski, Wojciech Jedruch, Individual based modeling and parameter estimation for a LotkaVolterra system, Mathematical Biosciences 
157 (12), 1999, 23-36.

http://dx.doi.org/10.1016/S0025-5564(98)10075-5

Bruno Buonomo, Andrea Di Liddo, Ivonne Sgura, A diffusive-convective model for the dynamics of population-toxicant interactions: some analytical and numerical results, Mathematical Biosciences Biosciences 157 (12), 1999, $37-64$.

http://dx.doi.org/10.1016/S0025-5564(98)10076-7

Tanya Kostova, Jia Li, Mark Friedman, Two models for competition between age classes, Mathematical Biosciences 157 (12), 1999, 65-89.

http://dx.doi.org/10.1016/S0025-5564(98)10077-9

Rafael Bravo de la Parra, Eva Sánchez, Ovide Arino, Pierre Auger, A discrete model with density dependent fast migration, Mathematical Biosciences 157 (12), 1999, 91-109.

http://dx.doi.org/10.1016/S0025-5564(98)10078-0

Luis Sanz, Rafael Bravo de la Parra, Variables aggregation in a time discrete linear model, Mathematical Biosciences 157 (12), 1999, 111-146. http://dx.doi.org/10.1016/S0025-5564(98)10079-2

L.M. Abia, J.C. López-Marcos, On the numerical integration of nonlocal terms for age-structured population models, Mathematical Biosciences 157 (12), 1999, 147-167.

http://dx.doi.org/10.1016/S0025-5564(98)10080-91

Oscar Angulo, J.C. Lpez-Marcos, Numerical schemes for size-structured population equations, Mathematical Biosciences 157 (12), 1999, 169-188. http://dx.doi.org/10.1016/S0025-5564(98)10081-0

Giovanna Chiorino, Pierre Auger, Jean-Luc Chass, Sandrine Charles, Behavioral choices based on patch selection: a model using aggregation methods, Mathematical Biosciences 157 (12), 1999, 189-216.

http://dx.doi.org/10.1016/S0025-5564(98)10082-2

B.W. Kooi, M.P. Boer, S.A.L.M. Kooijman, Resistance of a food chain to invasion by a top predator, Mathematical Biosciences Biosciences 157 (12), 1999, 217-236.

http://dx.doi.org/10.1016/S0025-5564(98)10083-4

Valko G. Petrov, Svetoslav G. Nikolov, Rheodynamic model of cardiac pressure pulsations, Mathematical Biosciences 157 (12), 1999, 237-252. http://dx.doi.org/10.1016/S0025-5564(98)10084-6

R.G. Seigneuric, J.-L. Chassé, P.M. Auger, A.L. Bardou, Role of the dispersion of refractoriness on cardiac reentries, Mathematical Biosciences 
157 (12), 1999, 253-267.

http://dx.doi.org/10.1016/S0025-5564(98)10085-8

Sergej V. Aksenov, Dynamics of the inducing signal for the SOS regulatory system in Escherichia coli after ultraviolet irradiation, Mathematical Biosciences 157 (12), 1999, 269-286.

http://dx.doi.org/10.1016/S0025-5564(98)10086-X

Milkes Yone Alvarenga, Koichi Sameshima, Luiz Antonio Baccalá, Hyun Mo Yang, Non-linear analysis of the rhythmic activity in rodent brains, Mathematical Biosciences 157 (12), 1999, 287-302.

http://dx.doi.org/10.1016/S0025-5564(98)10087-1

David Popivanov, A. Mineva, Testing procedures for non-stationarity and non-linearity in physiological signals, Mathematical Biosciences 157 (12), 1999, 303-320.

http://dx.doi.org/10.1016/S0025-5564(98)10088-3

Maria-Ana Popovici, Nicolae Mincu, Alexandru Popovici, A comparative study of processing simulated and experimental data in elastic laser light scattering, Mathematical Biosciences 157 (12), 1999, 321-344.

http://dx.doi.org/10.1016/S0025-5564(98)10089-5

Nikolay B. Kounov, Valko G. Petrov, Determination of erythrocyte aggregation, Mathematical Biosciences 157 (12), 1999, 345-356.

http://dx.doi.org/10.1016/S0025-5564(98)10090-1

Olivier Bernard, Jean-Luc Gouzé, Non-linear qualitative signal processing for biological systems: application to the algal growth in bioreactors, Mathematical Biosciences 157 (12), 1999, 357-372.

http://dx.doi.org/10.1016/S0025-5564(98)10091-3

Serdica Journal of Computing, Volume 4, Number 1, 2010 http://serdica-comp.math.bas.bg/index.php/serdicajcomputir.g/ issue/view/26

René Alt, Jean-Luc Lamotte, Svetoslav Markov, Stochastic Arithmetic Theory and Experiments, Serdica Journal of Computing 4, 1, 2010, 1-10

Maria Angelova, Stoyan Tzonkov, Tania Pencheva, Parameter Identification of a Fed-Batch Cultivation of S. Cerevisiae using Genetic Algorithms, Serdica Journal of Computing 4, 1, 2010, 11-18

V. Beschkov, T. Sapundzhiev, K. Petrov, E. Vasileva, Mathematical Modeling for Studying Microbial Processes Some Examples, Serdica Journal of Computing 4, 1, 2010, 19-28 
Gerd Bohlender, Ulrich Kulisch, A Mathematical Basis for an Interval Arithmetic Standard, Serdica Journal of Computing 4, 1, 2010, 29-42

Milen Borisov, Neli Dimitrova, One-Parameter Bifurcation Analysis of Dynamical Systems using Maple, Serdica Journal of Computing 4, 1, 2010, $43-56$

Aneta Karaivanova, Quasi-Monte Carlo Methods for some Linear Algebra Problems. Convergence and Complexity, Serdica Journal of Computing 4, 1, 2010, 57-72

Walter Krämer, Computer-Assisted Proofs and Symbolic Computations, Serdica Journal of Computing 4, 1, 2010, 73-84

Mikhail Ivanov Krastanov, High-Order Control Variations and SmallTime Local Controllability, Serdica Journal of Computing 4, 1, 2010, 85-92

Noël Malod-Dognin, Rumen Andonov, Nicola Yanev, Solving Maximum Clique Problem for Protein Structure Similarity, Serdica Journal of Computing 4, 1, 2010, 93-100

Nikolai L. Manev. Grid and Simulation of Digital Communication Systems, Serdica Journal of Computing 4, 1, 2010, 101-112

Antony T. Popov, A New Approach to Fuzzy Arithmetic, Serdica Journal of Computing 4, 1, 2010, 113-122

Evgenija Popova, Lyubomir Kolev, Walter Krämer, A Solver for ComplexValued Parametric Linear Systems, Serdica Journal of Computing 4, 1, 2010, 123-132

\section{Computers \& Mathematics with Applications, Volume 32, Issue 11, Pages 1-123 (December 1996)}

I. Aradi, P. Érdi, Signal generation and propagation in the olfactory bulb: Multicompartmental modeling, Computers \& Mathematics with Applications, Vol. 32, Issue 11, 1-27. http://dx.doi.org/10.1016/S0898-1221(96)00193-9

D. A. Mac Dónaill, N. H. Buttimore, The exploitation of assembly language instructions in biological text manipulation: I. Nucleotide sequences, Computers \& Mathematics with Applications, Vol. 32, Issue 11, 29-38. http://dx.doi.org/10.1016/S0898-1221(96)00194-0

N. H. Buttimore, D. A. Mac Dónaill, The exploitation of assembly language instructions in biological text manipulation: II. Amino acid sequences, Computers \& Mathematics with Applications, Vol. 32, Issue 11, 
39-45.

http://dx.doi.org/10.1016/S0898-1221(96)00195-2

C. E. A. Grigorescu, K. B. Radev, V. Chesaru, T. Necsoiu, I. Pricop, Thermal fluxes from the human body, Computers \& Mathematics with Applications, Vol. 32, Issue 11, 47-55.

http://dx.doi.org/10.1016/S0898-1221(96)00196-4

T. Kostova, J. Li, Oscillations and stability due to juvenile competitive effects on adult fertility, Computers \& Mathematics with Applications, Vol. 32 , Issue 11, 57-70.

http://dx.doi.org/10.1016/S0898-1221(96)00197-6

P. K. Maini, Spatial and spatiotemporal pattern formation in generalised turing systems, Computers \& Mathematics with Applications, Vol. 32 , Issue $11,71-77$.

http://dx.doi.org/10.1016/S0898-1221(96)00198-8

H. -S. Niwa, Mathematical model for the size distribution of fish schools, Computers \& Mathematics with Applications, Vol. 32, Issue 11, 79-88.

http://dx.doi.org/10.1016/S0898-1221(96)00199-X

K. B. Radev, C. E. A. Grigorescu, K. Berovski, B. Logofatu, Nonlinear signal processing in bioenergetics, Computers \& Mathematics with Applications, Vol. 32, Issue $11,89-91$.

http://dx.doi.org/10.1016/S0898-1221(96)00200-3

A. G. Rigas, D. S. Tsitsis, Spectral analysis techniques of stationary point processes: Extensions and applications to neurophysiological problems, Computers \& Mathematics with Applications, Vol. 32, Issue 11, 93-99.

http://dx.doi.org/10.1016/S0898-1221(96)00201-5

Z. Zlatev, J. Fenger, L. Mortensen, Relationships between emission sources and excess ozone concentrations, Computers \& Mathematics with Applications, Vol. 32, Issue 11, 101-123.

http://dx.doi.org/10.1016/S0898-1221(96)00202-7

\section{Computers \& Mathematics with Applications, Volume 64, Issue 3, Pages 161-390 (August 2012)}

Alicia Prieto-Langarica, Hristo V. Kojouharov, Benito M. Chen-Charpentier, Discrete and continuous approaches to modeling cell movement in the presence of a foreign stimulus, Computers \& Mathematics with Applications 64 
(3), 2012, 167-174.

http://dx.doi.org/10.1016/j.camwa.2011.11.058

Robert Strehl, Andriy Sokolov, Stefan Turek, Efficient, accurate and flexible finite element solvers for chemotaxis problems, Computers \& Mathematics with Applications 64 (3), 2012, 175-189.

http://dx.doi.org/10.1016/j.camwa.2011.12.040

Azmy S. Ackleh, Keng Deng, Xing Yang, Sensitivity analysis for a structured juvenile-adult model, Computers \& Mathematics with Applications 64 (3), 2012, 190-200.

http://dx.doi.org/10.1016/j.camwa.2011.12.053

Michael Chapwanya, Jean M.-S. Lubuma, Ronald E. Mickens, From enzyme kinetics to epidemiological models with Michaelis-Menten contact rate: Design of nonstandard finite difference schemes, Computers \& Mathematics with Applications 64 (3), 2012, 201-213.

http://dx.doi.org/10.1016/j.camwa.2011.12.053

Peter A. Djondjorov, Vassil M. Vassilev, Ivaïlo M. Mladenov, Deformation of injected vesicles adhering onto flat rigid substrates, Computers \& Mathematics with Applications 64 (3), 2012, 214-220. http://dx.doi.org/10.1016/j.camwa.2012.01.044

Maria Angelova, Krassimir Atanassov, Tania Pencheva, Purposeful model parameters genesis in simple genetic algorithms, Computers \& Mathematics with Applications 64 (3), 2012, 221-228.

http://dx.doi.org/10.1016/j.camwa.2012.01.047

Angel G. Angelov, Maroussia Slavtchova-Bojkova, Bayesian estimation of the offspring mean in branching processes: Application to infectious disease data, Computers \& Mathematics with Applications 64 (3), 2012, $229-235$.

http://dx.doi.org/10.1016/j.camwa.2012.01.049

A. Gómez-Corral, M. López García, On the number of births and deaths during an extinction cycle, and the survival of a certain individual in a competition process, Computers \& Mathematics with Applications 64 (3), 2012, 236-259.

http://dx.doi.org/10.1016/j.camwa.2012.01.058

Gaik Ambartsoumian, Inversion of the V-line Radon transform in a disc and its applications in imaging, Computers \& Mathematics with Applications 64 (3), 2012, 260-265.

http://dx.doi.org/10.1016/j.camwa.2012.01.059 
Dessislava Jereva, Ilza Pajeva, Tania Pencheva, Data extraction moduleA supplementary tool for the AMMOS_ProtLig software package, Computers \& Mathematics with Applications 64 (3), 2012, 266-271.

http://dx.doi.org/10.1016/j.camwa.2012.01.060

Elena Lilkova, Genoveva Nacheva, Peicho Petkov, Petko Petkov, Stoyan Markov, Nevena Ilieva, Leandar Litov, Metadynamics study of mutant human interferon-gamma forms, Computers \& Mathematics with Applications 64 (3), 2012, 272-277.

http://dx.doi.org/10.1016/j.camwa.2012.01.061

I. Cimrák, M. Gusenbauer, T. Schrefl, Modelling and simulation of processes in microfluidic devices for biomedical applications, Computers \& Mathematics with Applications 64 (3), 2012, 278-288.

http://dx.doi.org/10.1016/j.camwa.2012.01.062

Thomas Guillon, Yves Dumont, Thierry Fourcaud, Numerical methods for the biomechanics of growing trees, Computers \& Mathematics with Applications 64 (3), 2012, 289-309.

http://dx.doi.org/10.1016/j.camwa.2012.02.040

Luís Almeida, Patrizia Bagnerini, Abderrahmane Habbal, Modeling actin cable contraction, Computers \& Mathematics with Applications 64 (3), 2012, 310-321.

http://dx.doi.org/10.1016/j.camwa.2012.02.041

R. Ivanova, G. Simeonov, A formula for the oxygen uptake of thin tissue slice in terms of its surface oxygen tension, Computers \& Mathematics with Applications 64 (3), 2012, 322-336.

http://dx.doi.org/10.1016/j.camwa.2012.02.044

Gergana Bencheva, Computer modelling of haematopoietic stem cells migration, Computers \& Mathematics with Applications 64 (3), 2012, 337349.

http://dx.doi.org/10.1016/j.camwa.2012.02.045

Rene Alt, Svetoslav Markov, Theoretical and computational studies of some bioreactor models, Computers \& Mathematics with Applications 64 (3), 2012, 350-360.

http://dx.doi.org/10.1016/j.camwa.2012.02.046

Milen Borisov, Neli Dimitrova, Venko Beschkov, Stability analysis of a bioreactor model for biodegradation of xenobiotics, Computers \& Mathematics with Applications 64 (3), 2012, 361-373.

http://dx.doi.org/10.1016/j.camwa.2012.02.067 
Roumen Anguelov, Yves Dumont, Jean Lubuma, Mathematical modeling of sterile insect technology for control of anopheles mosquito, Computers \& Mathematics with Applications 64 (3), 2012, 374-389.

http://dx.doi.org/10.1016/j.camwa.2012.02.068

\section{Computers \& Mathematics with Applications, Volume 66, Issue 9, Pages 1533-1726 (November 2013)}

Maoxing Liu, Gergely Röst, Gabriella Vas, SIS model on homogeneous networks with threshold type delayed contact reduction, Computers \& Mathematics with Applications, Vol. 66, Issue 9 (2013), 1534-1546.

http://dx.doi.org/10.1016/j.camwa.2013.02.009

V. V. Akimenko, Yu. V. Zahorodnii, A. L. Boyko, Identification of parameters of evolutionary model of monocyclic cells aggregation with the hop plants example, Computers \& Mathematics with Applications, Vol. 66, Issue 9 (2013), 1547-1553.

http://dx.doi.org/10.1016/j.camwa.2013.02.009

Merab Svanadze, Antonio Scalia, Mathematical problems in the coupled linear theory of bone poroelasticity, Computers \& Mathematics with Applications, Vol. 66, Issue 9 (2013), 1554-1566.

http://dx.doi.org/10.1016/j.camwa.2013.01.046

Gaik Ambartsoumian, Sunghwan Moon, A series formula for inversion of the V-line Radon transform in a disc, Computers \& Mathematics with Applications, Vol. 66, Issue 9 (2013), 1567-1572.

http://dx.doi.org/10.1016/j.camwa.2013.01.039

Claudia Timofte, Multiscale analysis of diffusion processes in composite media, Computers \& Mathematics with Applications, Vol. 66, Issue 9 (2013), 1573-1580.

http://dx.doi.org/10.1016/j.camwa.2012.12.003

Yves Coudière, Mazen Saad, Alexandre Uzureau, Analysis of a finite volume method for a bone growth system in vivo, Computers \& Mathematics with Applications, Vol. 66, Issue 9 (2013), 1581-1594.

http://dx.doi.org/10.1016/j.camwa.2013.02.002

Diego de Pereda, Sergio Romero-Vivo, Beatriz Ricarte, Jorge Bondia, Guaranteed computation methods for compartmental in-series models under uncertainty, Computers \& Mathematics with Applications, Vol. 66, Issue 9 (2013), 1595-1605.

http://dx.doi.org/10.1016/j.camwa.2013.03.008 
Alicia Prieto-Langarica, Hristo V. Kojouharov, Benito M. Chen-Charpentier, Upscaling from discrete to continuous mathematical models of two interacting populations, Computers \& Mathematics with Applications, Vol. 66, Issue 9 (2013), 1606-1612.

http://dx.doi.org/10.1016/j.camwa.2013.02.010

Ian P. Martines, Hristo V. Kojouharov, James P. Grover, Nutrient recycling and allelopathy in a gradostat, Computers \& Mathematics with Applications, Vol. 66, Issue 9 (2013), 1613-1626.

http://dx.doi.org/10.1016/j.camwa.2013.02.010

Gregory Toole, Monica K. Hurdal, Turing models of cortical folding on exponentially and logistically growing domains, Computers \& Mathematics with Applications, Vol. 66, Issue 9 (2013), 1627-1642.

http://dx.doi.org/10.1016/j.camwa.2013.03.019

Roumen Anguelov, Jan Harm van der Walt, Algebraic and topological structure of some spaces of set-valued maps, Computers \& Mathematics with Applications, Vol. 66, Issue 9 (2013), 1643-1654. http://dx.doi.org/10.1016/j.camwa.2013.04.008

Evgenija D. Popova, Inner estimation of the parametric tolerable solution set, Computers \& Mathematics with Applications, Vol. 66, Issue 9 (2013), 1655-1665.

http://dx.doi.org/10.1016/j.camwa.2013.04.007

Nikolay K. Vitanov, Zlatinka I. Dimitrova, Kaloyan N. Vitanov, Traveling waves and statistical distributions connected to systems of interacting populations, Computers \& Mathematics with Applications, Vol. 66, Issue 9 (2013), 1666-1684.

http://dx.doi.org/10.1016/j.camwa.2013.04.002

Azmy S. Ackleh, József Z. Farkas, On the net reproduction rate of continuous structured populations with distributed states at birth, Computers \& Mathematics with Applications, Vol. 66, Issue 9 (2013), 1685-1694. http://dx.doi.org/10.1016/j.camwa.2013.04.010

Claire Dufourd, Yves Dumont, Impact of environmental factors on mosquito dispersal in the prospect of Sterile Insect Technique control, Computers \& Mathematics with Applications, Vol. 66, Issue 9 (2013), 16951715 .

http://dx.doi.org/10.1016/j.camwa.2013.03.024

Elena Nikolova, Ivan Jordanov, Nikolay K. Vitanov, Dynamical features of the quasi-stationary microRNA-mediated protein translation pro- 
cess, Computers \& Mathematics with Applications, Vol. 66, Issue 9 (2013), 1716-1725.

http://dx.doi.org/10.1016/j.camwa.2013.04.021

\section{Computers \& Mathematics with Applications, Volume 68, Issue 9, Pages 903-1082 (November 2014)}

A. Bellouquid, M. C. H.-Chaoui, Asymptotic analysis of a nonlinear integrodifferential system modeling the immune response, Computers \& Mathematics with Applications, Vol. 68, Issue 9 (2014), 905-914.

http://dx.doi.org/10.1016/j.camwa.2014.05.018

K. Nah, Y. Nakata, G. Röst, Malaria dynamics with long incubation period in hosts, Computers \& Mathematics with Applications, Vol. 68, Issue 9 (2014), 915-930.

http://dx.doi.org/10.1016/j.camwa.2014.05.001

R. Anguelov, S. Garba, S. Usaini, Backward bifurcation analysis of epidemic model with partial immunity, Computers \& Mathematics with Applications, Vol. 68, Issue 9 (2014), 931-940.

http://dx.doi.org/10.1016/j.camwa.2014.06.010

O. Angulo, J. C. Lopez-Marcos, MA Lopez-Marcos, Analysis of an efficient integrator for a size-structured population model with a dynamical resource, Computers \& Mathematics with Applications, Vol. 68, Issue 9 (2014), 941-961.

http://dx.doi.org/10.1016/j.camwa.2014.04.009

N. K. Vitanov, K. N. Vitanov, Population dynamics in presence of state dependent fluctuations, Computers \& Mathematics with Applications, Vol. 68, Issue 9 (2014), 962-971.

http://dx.doi.org/10.1016/j.camwa.2014.03.006

X. Dong, H. V. Kojouharov, J. P. Grover, Mathematical models of nutrient recycling and toxin production in a gradostat, Computers \& Mathematics with Applications, Vol. 68, Issue 9 (2014), 972-985.

http://dx.doi.org/10.1016/j.camwa.2014.02.026

N. Dimitrova, Mikhail Krastanov, Model-based optimization of biogas production in an anaerobic biodegradation process, Computers \& Mathematics with Applications, Vol. 68, Issue 9 (2014), 986-993.

http://dx.doi.org/10.1016/j.camwa.2014.04.006

E. D. Popova, Improved enclosure for eome parametric solution sets with linear shape, Computers \& Mathematics with Applications, Vol. 68, 
Issue 9 (2014), 994-1005.

http://dx.doi.org/10.1016/j.camwa.2014.04.005

J. H. van der Walt, Linear and quasi-linear spaces of set-valued maps, Computers \& Mathematics with Applications, Vol. 68, Issue 9 (2014), 1006-1015.

http://dx.doi.org/10.1016/j.camwa.2014.03.007

Rim Gouia-Zarrad, Analytical reconstruction formula for n-dimensional conical Radon transform, Computers \& Mathematics with Applications, Vol. 68, Issue 9 (2014), 1016-1023.

http://dx.doi.org/10.1016/j.camwa.2014.04.019

C. Timofte, Homogenization results for ionic transport in periodic porous media, Computers \& Mathematics with Applications, Vol. 68, Issue 9 (2014), 1024-1031.

http://dx.doi.org/10.1016/j.camwa.2014.03.009

M. Ibrahim, M. Saad, On the efficacy of a control volume finite element method for the capture of patterns for a volume-filling chemotaxis model, Computers \& Mathematics with Applications, Vol. 68, Issue 9 (2014), $1032-1051$.

http://dx.doi.org/10.1016/j.camwa.2014.03.010

G. Chamoun, M. Saad, R. Talhouk, A coupled anisotropic chamotaxisfluid model: the case of two-sidely degenerate diffusion, Computers \& Mathematics with Applications, Vol. 68, Issue 9 (2014), 1052-1070.

http://dx.doi.org/10.1016/j.camwa.2014.04.010

M. Chapwanya, R. E. Mickens, J. Lubuma, Positivity-preserving nonstandard finite difference schemes for cross-diffusion equations in biosciences, Computers \& Mathematics with Applications, Vol. 68, Issue 9 (2014), 1071-1082.

http://dx.doi.org/10.1016/j.camwa.2014.04.021

\section{Biotechnology \& Biotechnological Equipment vol 2 (2) (2012), 3242-3320, BIOINFORMATICS (selected papers from BioMath 2011)}

Beschkov V., Ts. Sapundzhiev, I. Angelov, Modelling of Biogas Production from Glycerol by Anaerobic Process in a Baffled Multi-Stage Digestor, Biotechnology \& Biotechnological Equipment, 26(5), 2012, 3244-3248. http://dx.doi.org/10.5504/bbeq.2012.0061 
Ilkova T., M. Petrov, O. Roeva, Optimization of a Whey Bioprocess using Neuro-Dynamic Programming Strategy, Biotechnology \& Biotechnological Equipment, 26(5), 2012, 3249-3253.

http://dx.doi.org/10.5504/bbeq.2012.0063

Pavlov Y., P. Vassilev, Preferences and Determination of the Nominal Growth Rate of a Fed-Batch Process: Control Design of Complex Processes, Biotechnology \& Biotechnological Equipment, 26(5), 2012, 3254-3259.

http://dx.doi.org/10.5504/bbeq.2012.0064

Petrova E., Assessment of the Influence of $\mathrm{Ca}^{2+}$ and $\mathrm{pH}$ on Bacterial Growth of Acidithiobacillus ferrooxidans, Biotechnology \& Biotechnological Equipment, 26(5), 2012, 3260-3266.

http://dx.doi.org/10.5504/bbeq.2012.0066

Roeva O., T. Slavov, PID Controller Tuning Based on Metaheuristic Algorithms for Bioprocess Control, Biotechnology \& Biotechnological Equipment, 26(5), 2012, 3267-3277.

http://dx.doi.org/10.5504/bbeq.2012.0065

Yemendzhiev H., P. Zlateva, Z. Alexieva, Comparison of the Biodegradation Capacity of Two Fungal Strains Toward a Mixture of Phenol and Cresol by Mathematical Modeling, Biotechnology \& Biotechnological Equipment, 26(5), 2012, 3278-3281.

http://dx.doi.org/10.5504/bbeq.2012.0062

Khanchouch K., M. R. Hajlaoui, H. Kutucu, A Biomathematical Model for Phoma tracheiphila Citrus Resistance Screening, Biotechnology \& Biotechnological Equipment, 26(5), 2012, 3282-3285.

http://dx.doi.org/10.5504/bbeq.2012.0073

Antonova N., On Some Mathematical Models in Hemorheology, Biotechnology \& Biotechnological Equipment, 26(5), 2012, 3286-3291.

http://dx.doi.org/10.5504/bbeq.2012.0069

Kirilova M., D. Pashkouleva, V. Kavardzhikov, A Selection of Hernia Meshes on the Basis of Experimental Results for Abdominal Layers, Biotechnology \& Biotechnological Equipment, 26(5), 2012, 3292-3295.

http://dx.doi.org/10.5504/bbeq.2012.0068

Konovski P., A Common Approach to Finding the Optimal Scenarios of a Markov Stochastic Process over a Phylogenetic Tree, Biotechnology \& Biotechnological Equipment, 26(5), 2012, 3296-3301.

http://dx.doi.org/10.5504/bbeq.2012.0071

Simeonova V., I. Popov, D. Vassilev, Estimation of Sequencing Error 
Rates Present in Genome Databases, Biotechnology \& Biotechnological Equipment, 26(5), 2012, 3302-3305.

http://dx.doi.org/10.5504/bbeq.2012.0070

Rangasamy P., S. Hadjitodorov, K. Atanassov, P. Vassilev, Generalized Net Model of an Intuitionistic Fuzzy Clustering Technique for Biomedical Data, Biotechnology \& Biotechnological Equipment, 26(5), 2012, 33063309.

http://dx.doi.org/10.5504/bbeq.2012.0072

Kirilov K., I. Ivanov, A Programme for Determination of Codons and Codons Context Frequency of Occurrence in Sequenced Genomes, Biotechnology \& Biotechnological Equipment, 26(5), 2012, 3310-3314.

http://dx.doi.org/10.5504/bbeq.2012.0074

Nikolov S., J. V. Gonzalez, M. Nenov, O. Wolkenhauer, Dynamics of a Mirna Model with Two Delays, Biotechnology \& Biotechnological Equipment, 26(5), 2012, 3315-3320.

http://dx.doi.org/10.5504/bbeq.2012.0067

\section{Journal Biomath vol. 1/1 (2012)}

A. Prieto-Langarica, H. Kojouharov, L. Tang, Constructing One-Dimensional Continuous Models from Two-Dimensional Discrete Models of Medical Implants, Biomath 1 (2012), 1209041, http://dx.doi.org/10.11145/j.biomath.2012.09.041

C. Timofte, Multiscale Analysis of Composite Structures, Biomath 1 (2012), 1209021, http://dx.doi.org/10.11145/j.biomath.2012.09.021

P. Hingley, Exploring Family Relations between International Patent Applications, Biomath 1 (2012), 1209031

http://dx.doi.org/10.11145/j.biomath.2012.09.031

N. Al-Asuoad, R. Anguelov, K. Berven, M. Shillor, Model and Simulations of a Wood Frog Population, Biomath 1 (2012), 1209032, http://dx.doi.org/10.11145/j.biomath.2012.09.032

N. Filmann, E. Herrmann, Modeling of Viral Dynamics after Liver Transplantation in Patients with Chronic Hepatitis B and D, Biomath 1 (2012), 1209022, http://dx.doi.org/10.11145/j.biomath.2012.09.022

D. Bon, C. Stephan, O. Keppler, E. Herrmann, Viral Dynamic Model of Antiretroviral Therapy Including the Integrase Inhibitor Raltegravir in 
Patients with HIV-1, Biomath 1 (2012), 1209251,

http://dx.doi.org/10.11145/j.biomath.2012.09.251

H. Umeo, A. Nomura, A State-Efficient Zebra-Like Implementation of Synchronization Algorithms for 2D Rectangular Cellular Arrays, Biomath 1 (2012), 1209022, http://dx.doi.org/10.11145/j.biomath.2012.09.022

G. Toole, M. Hurdal, Growth in a Turing Model of Cortical Folding, Biomath 1 (2012), 1209252, http://dx.doi.org/10.11145/j.biomath.2012.09.252

N. Vitanov, Z. Dimitrova, On Waves and Distributions in Population Dynamics, Biomath 1 (2012), 1209253,

http://dx.doi.org/10.11145/j.biomath.2012.09.253

Y. Coudiere, M. Saad, A. Uzureau, An Upstream Finite Volume Scheme for a Bone Healing Model, Biomath 1 (2012), 1209254, http://dx.doi.org/10.11145/j.biomath.2012.09.254

D. Knipl, G. Röst, Multiregional SIR Model with Infection during Transportation, Biomath 1 (2012), 1209255, http://dx.doi.org/10.11145/j.biomath.2012.09.255

A. Denes, G. Röst, Structure of the Global Attractors in a Model for Ectoparasite-Borne Diseases, Biomath 1 (2012), 1209256, http://dx.doi.org/10.11145/j.biomath.2012.09.256

\section{Journal Biomath vol. 1/2 (2012)}

D. de Pereda, S. Romero-Vivó, J. Bondia, On the Computation of Output Bounds for Compartmental in-Series Models under Parametric Uncertainty, Biomath 1 (2012), 1210043, http://dx.doi.org/10.11145/j.biomath.2012.10.043

O. Roeva, T. Trenkova, Modelling of a Fed-batch Culture Applying Simulated Annealing, Biomath 1 (2012), 1211114, http://dx.doi.org/10.11145/j.biomath.2012.11.114

N. Pesheva, J. Brankov, Position-Induced Phase Change in a TASEP with a Double-Chain Section (a Model of Biological Transport), Biomath 1 (2012), 1211211, http://dx.doi.org/10.11145/j.biomath.2012.11.211

P. Petrov, M. Krachounov, O. Kulev, M. Nisheva, D. Vassilev, Predicting and Scoring Links in Anatomical Ontology Mapping, Biomath 1 (2012), 
1211117,

http://dx.doi.org/10.11145/j.biomath.2012.11.117

M. Svanadze, A. Scalia, Mathematical Problems in the Theory of Bone Poroelasticity, Biomath 1 (2012), 1211225,

http://dx.doi.org/10.11145/j.biomath.2012.11.225

M. Liu, G. Rost, Dynamics of an SIS Model on Homogeneous Networks with Delayed Reduction of Contact Numbers, Biomath 1 (2012), 1210045, http://dx.doi.org/10.11145/j.biomath.2012.10.045

J. Tewa, R. D. Demasse, S. Bowong, Predator-Prey Model with Prey Harvesting, Holling Response Function of Type III and SIS Disease, Biomath 1 (2012), 1210231, http://dx.doi.org/10.11145/j.biomath.2012.10.231

C. Dufourd, Y. Dumont, Modeling and Simulations of Mosquito Dispersal. The Case of Aedes albopictus, Biomath 1 (2012), 1209262, http://dx.doi.org/10.11145/j.biomath.2012.09.262

Fabris-Rotelli, Nonlinear Filters and Characterization of the Discrete Pulse Transform of Images, Biomath 1 (2012), 1211119, http://dx.doi.org/10.11145/j.biomath.2012.11.119

K. Liolios, S. Radev, A. Liolios, I. Georgiev, K. Georgiev, A Linear Complementarity Numerical Approach to the Non-Convex Problem of Structures Environmentally Damaged and Strengthened by Cable-bracings, Biomath 1 (2012), 1212107,

http://dx.doi.org/10.11145/j.biomath.2012.12.107

\section{Journal Biomath vol. 2/1 (2013)}

Elena Nikolova, Ivan Jordanov, Nikolay Vitanov, Dynamical Analysis of the MicroRNA - Mediated Protein Translation Process, Biomath 2 (2013), 1210071

http://dx.doi.org/10.11145/j.biomath.2012.10.071

Priti Kumar Roy, Abhirup Datta, Impact of Perfect Drug Adherence on Immunopathogenic Mechanism for Dynamical System of Psoriasis, Biomath 2 (2013), 1212101, http://dx.doi.org/10.11145/j.biomath.2012.12.101

Antony Popov, Simeon Stoykov, Rough Sets in Biomedical Informatics, Biomath 2 (2013), 1212127, http://dx.doi.org/10.11145/j.biomath.2012.12.127 
Edward H. Flach, John Norbury, Santiago Schnell, More than Skew: Asymmetric Wave Propagation in a Reaction-Diffusion-Convection System, Biomath 2 (2013), 1303027, http://dx.doi.org/10.11145/j.biomath.2013.03.027

Nikolay Kyurkchiev, Anton Iliev, On Some Multipoint Methods Arrising from Optimal in the Sense of Kung-Traub Algorithms for Numerical Solution of Nonlinear Equations, Biomath 2 (2013), 1305155, http://dx.doi.org/10.11145/j.biomath.2013.05.155

Samuel Bowong, Yves Dumont, Jean Jules Tewa, A patchy model for Chikungunya-like diseases, Biomath 2 (2013), 1307237, http://dx.doi.org/10.11145/j.biomath.2013.07.237

Marc R Roussel, On the Distribution of Transcription Times, Biomath 2 (2013), 1307247, http://dx.doi.org/10.11145/j.biomath.2013.07.247

Laurens Bakker, Andrew Poelstra, Calculating Hyphal Surface Area in Models of Fungal Networks, Biomath 2 (2013), 1309087, http://dx.doi.org/10.11145/j.biomath.2013.09.087

Sorana D. Bolboaca, Lorentz Jäntschi, Quantitative Structure-Activity Relationships: Linear Regression Modelling and Validation Strategies by Example, Biomath 2 (2013), 1309089, http://dx.doi.org/10.11145/j.biomath.2013.09.089

\section{Journal Biomath vol. 2/2 (2013)}

Jan Harm van der Walt, The Linear Space of Hausdorff Continuous Interval Functions, Biomath 2 (2013), 1311261, http://dx.doi.org/10.11145/j.biomath.2013.11.261

Claire Dufourd, Christopher Weldon, Roumen Anguelov, Yves Dumont, Parameter Identification in Population Models for Insects Using Trap Data, Biomath 2 (2013), 1312061, http://dx.doi.org/10.11145/j.biomath.2013.12.061

Georges Chamoun, Mazen Saad, Raafat Talhouk, Mathematical and Numerical Analysis of a Modified Keller-Segel Model with General Diffusive Tensors, Biomath 2 (2013), 1312071, http://dx.doi.org/10.11145/j.biomath.2013.12.071

Diána H Knipl, Gergely Röst, Backward Bifurcation in SIVS Model with Immigration of Non-Infectives, Biomath 2 (2013), 1312051, http://dx.doi.org/10.11145/j.biomath.2013.12.051 
Stefanie Sonner, A Class of Mathematical Models Describing Processes in Spatially Heterogeneous Biofilm Communities, Biomath 2 (2013), 1312311, http://dx.doi.org/10.11145/j.biomath.2013.12.311

Rene Alt, Jean-Luc Lamotte, Stochastic Arithmetic as a Tool to Study the Stability of Biological Models, Biomath 2 (2013), 1312291, http://dx.doi.org/10.11145/j.biomath.2013.12.291

Svetoslav Marinov Markov, Cell Growth Models Using Reaction Schemes: Batch Cultivation, Biomath 2 (2013), 1312301, http://dx.doi.org/10.11145/j.biomath.2013.12.301

Claudia Timofte, Multiscale Analysis of Ionic Transport in Periodic Charged Media, Biomath 2 (2013), 1312302, http://dx.doi.org/10.11145/j.biomath.2013.12.302

\section{Journal Biomath vol. 3/1 (2014)}

Beata Zduniak, Numerical Analysis of the Coupled Modified Van Der Pol Equations in a Model of the Heart Action, Biomath 3 (2014), 1312281, http://dx.doi.org/10.11145/j.biomath.2013.12.281

Oscar Angulo, J.C. Lopez-Marcos, M.A. Lopez-Marcos, Numerical Analysis of a Size-Structured Population Model with a Dynamical Resource, Biomath 3 (2014), 1403241, http://dx.doi.org/10.11145/j.biomath.2014.03.241

Elena Nikolova, Ivan Jordanov, Nikolay Vitanov, On Nonlinear Dynamics of the STAT5a Signaling Protein, Biomath 3 (2014), 1404131, http://dx.doi.org/10.11145/j.biomath.2014.04.131

David Fotsa, Elvis Houpa, David Bekolle, Christopher Thron, Michel Ndoumbe, Mathematical Modelling and Optimal Control of Anthracnose, Biomath 3 (2014), 1404161, http://dx.doi.org/10.11145/j.biomath.2014.04.161

Krasimira Kostadinova, Leda Minkova, On a Bivariate Poisson Negative Binomial Risk Process, Biomath 3 (2014), 1404211, http://dx.doi.org/10.11145/j.biomath.2014.04.211

Valaire Yatat, Yves Dumont, Jean Jules Tewa, Pierre Couteron, Samuel Bowong, Mathematical Analysis of a Size Structured Tree-Grass Competition Model for Savanna Ecosystems, Biomath 3 (2014), 1404212, http://dx.doi.org/10.11145/j.biomath.2014.04.212

Daniel Coffield, Anna Maria Spagnuolo, Steady State Stability Analysis of a Chagas Model, Biomath 3 (2014), 1405261, 
http://dx.doi.org/10.11145/j.biomath.2014.05.261

Nadja Radchenkova, Margarita Kambourova, Spasen Vassilev, Rene Alt, Svetoslav Markov, On the Mathematical Modelling of EPS Production by a Thermophilic Bacterium, Biomath 3 (2014), 1407121, http://dx.doi.org/10.11145/j.biomath.2014.07.121

Mamadou Diouf, Abderrahman Iggidr, Mamadou Sy, Global Stability of an Epidemic Model with two Infected Stages and Mass-Action Incidence, Biomath 3 (2014), 1407211, http://dx.doi.org/10.11145/j.biomath.2014.07.211

\section{Journal Biomath vol. 3/2 (2014)}

A. Tchuinté Tamen, J. J. Tewa, P. Couteron, S. Bowong, Y. Dumont, A Generic Modeling of Fire Impact in a Tree-Grass Savanna Model, Biomath 3 (2014), 1407191, http://dx.doi.org/10.11145/j.biomath.2014.07.191

Svetoslav G. Nikolov, Modelling and Analysis of miRNA Regulation, Biomath 3 (2014), 1407231, http://dx.doi.org/10.11145/j.biomath.2014.07.231

Olaposi Idowu Omotuyi, Hiroshi Ueda, Descriptor-based Fitting of LPA3 Inhibitors into a Single Predictive Mathematical Model, Biomath 3 (2014), 1410061, http://dx.doi.org/10.11145/j.biomath.2014.10.061

Ana Vivas-Barber, Carlos Castillo-Chavez, Ernest Barany, Dynamics of an SAIQR Influenza Model, Biomath 3 (2014), 1409251, http://dx.doi.org/10.11145/j.biomath.2014.09.251

N. Shivaranjani, J.J.H. Miller, S.Valarmathi, A Parameter Uniform Almost First Order Convergent Numerical Method for a Semi-Linear System of Singularly Perturbed Delay Differential Equations, Biomath 3 (2014), 1411041 , http://dx.doi.org/10.11145/j.biomath.2014.11.041

Daniel J. Coffield Jr., Ken Kuttler, Xianggui Qu, Jorge Rabinovich, Meir Shillor, Anna Maria Spagnuolo, Alexandra Zetye, A Model for the Transmission of Chagas Disease with Random Inputs, Biomath 3 (2014), 1411071 , http://dx.doi.org/10.11145/j.biomath.2014.11.071

Peter Rashkov, Regular and Discontinuous Solutions in a ReactionDiffusion Model for Hair Follicle Spacing, Biomath 3 (2014), 1411111, 
http://dx.doi.org/10.11145/j.biomath.2014.11.111

Kharananda Sharma, Bradley J. Roth, How Compressibility Influences the Mechanical Bidomain Model, Biomath 3 (2014), 1411171, http://dx.doi.org/10.11145/j.biomath.2014.11.171 